\title{
Production of Nitrogen Fixing and Phosphorous Solubilizing Liquid Bio-fertilizer for the Improves of the Crops Growth and Yield
}

\author{
Zeynu Shamil ${ }^{1, *}$, Rezika Tofike ${ }^{2}$ \\ ${ }^{1}$ Department of Chemical Engineering, College of Engineering, Awol Wolkite University, Wolkite, Ethiopia \\ ${ }^{2}$ Department of Chemical Engineering, College of Engineering, Abate Wolkite University, Wolkite, Ethiopia
}

Email address:

zeynu2006@gmail.com (Z. Shamil)

${ }^{*}$ Corresponding author

To cite this article:

Zeynu Shamil, Rezika Tofike. Production of Nitrogen Fixing and Phosphorous Solubilizing Liquid Bio-fertilizer for the Improves of the Crops Growth and Yield. American Journal of Chemical and Biochemical Engineering. Vol. 9, No. 3, 2021, pp. 61-67. doi: 10.11648/j.mc.20210903.13

Received: August 18, 2021; Accepted: September 7, 2021; Published: September 26, 2021

\begin{abstract}
Bio-fertilizers are the result of fermentation process that including efficient life soil microorganisms specially bacteria and fungi. They reform plant growth and productivity through deliver of easily utilizable nutrients. They are costeffective and eco-friendly bio-inoculants having great potential to enhance agricultural crop yield in sustainable path. Biofertilizers are classified into different types based on their purpose such as nitrogen-fixing, phosphate-solubilizing, kmobilizing, and other plant growth-promoting bio-fertilizers. Promoting plant growth by different way Solid-state fermentation (15\%-40\% moisture content) and submerged (liquid medium 95\%moisture content) fermentation are two main types of fermentation used sample for the production of bio-fertilizers. Each type of bio-fertilizer was prepared by selection of efficient microbial strain that can be isolated from environmental sample in this study by using direct manipulation of the environmental sample (in quit) with selective microbial nutrient then by using absorption of ingredients we can analysis bacterial growth curve analysis. Finally, we do that affirmation of microbial sp. by using morphological and biochemical test. Its cultivation using specific nutrient medium by formulations of using liquid base (broth). So Bio-fertilizers was recommended and an effective substitutable matter for socio economic and environmental friend of chemical fertilizers (CF) for farm land productivity.
\end{abstract}

Keywords: Rhizobium, Bio Fertilizer, Plant Growth, Nutrient Agar

\section{Introduction}

Microorganisms employed to improve availability of nutrients, nitrogen by fixing atmospheric $\mathrm{N}_{2}$ (atmospheric nitrogen convert in to $\mathrm{NH}_{3}$ (Ammonia) (e.g. rhizobium sp), phosphorus solubilized (e.g. Pseudomonas sp./azatobacter) and K. mobilizing to the crops are called bio fertilizer. [13, 7] in other definition of bio fertilizer was a substance which contains living microorganism function is in long duration, causing improvement of the soil fertility, Bio fertilizers are microorganisms that enhance nutrient availability to plants, contributing to plant nutrition either by facilitating nutrient uptake or by increasing primary nutrient availability in the rhizosphere. it maintains the natural habitat of the soil. $[3,6$,
8] The term "bio-fertilizer" is made up of two words, 'Bio' means living and 'fertilizer' means a product which provides nutrients in usable form. they help in fixing or solubilizing the nutrients present in air or in the soil which is then made available to the plants. $[9,8]$

Bio fertilizers also include organic fertilizers (like manure, etc.), which are rendered in an available form due to the interaction of microorganisms or due to their association with plants. Bio fertilizers also include organic fertilizers (manure, etc.), which are rendered in an available form due to the interaction of microorganisms or due to their association with plants. $[6,11]$

The various strain of micro- organism having prospective study show that of application as bio fertilizer are: bacteria 
(e.g. Rhizobium spp., Azotobacter), fungi (e.g. mycorrhizae like glomus), blue-green algae or nitrogen-fixing cyanobacteria, (e.g. anabena, etc.) and azolla (e.g. a fern containing symbiotic anabena azallae). [10, 15] Bio fertilizer are products of elected valuable advantages like Longer shelflife (12-24) months, no contamination, no loss of properties due to storage up to $35^{\circ} \mathrm{C}$, greater potentials to fight with native population, easy identification by typical fermented smell, better survival on seeds and soil, very much easy to use by the farmer and high commercial revenues. $[2,5,10]$

Organisms to be often used while bio fertilizers component be nitrogen fixers ( $\mathrm{N}$ - fixer), potassium mobilize and phosphorus solubilize by the formulation of mold and fungi. Nearly all of the bacteria included in bio fertilizer include a close association through plant roots. Rhizobium has symbiotic interaction by legume roots and rhizo-bacteria in habit on roots surface or in rhizosphere soil. The phosphormicroorganism mainly bacteria and fungi make insoluble phosphorus available to the plants [7].

Bio fertilizers also include organic fertilizers (manure, etc.), which are rendered in an available form due to the interaction of microorganisms or due to their association with plants. Bio fertilizers also include organic fertilizers (manure, etc.), which are rendered in an available form due to the interaction of microorganisms or due to their association with plants. [12, 13]

Live microbes which help to reform/amendment of soil, plant growth and productivity mainly through supply of plant nutrients. Bio fertilizers are also known as microbial inoculants or bio inoculants $[5,3]$.

Synthetic/chemical manure not only provides essential nutrients to food crops but also provides simply available manner. So, these fertilizers can rapidly improve the increase and efficiency of food crops and are quick to gain popularity. [11]

Howeve broad use likewise this bio-fertilizer is environment friendly and gives uniform results for most of the agricultural crops and directly reduces the use of chemical fertilizer by 15 to $40 \%$. The shelf life of the liquid bio fertilizer is higher (in the range of one to two years) compared to that of solid matrix base bio-fertilizer. There is a growing demand for organic foods in the global market.[13]

Of such fertilizer leads to serious concerns. Nitrate leakage and exterior/soil water toxic waste due to augmented use of fertilizer is straight linked to human health problems. Likewise, fresh water pollution through chemical fertilizer/fertilizer remains be single of the main cause of eutrophication. [1, 9]

A number of reports include examine the different bacterial species to solubilize insoluble organic phosphate compounds such as tricalcium phosphate, dicalcium phosphate, hydroxyapatit, and rock phosphate. Among bacterial genera with this capacity are Pseudomonas, Bacillus, Rhizobium, Burkholderi, Achromobacter, Agrobacterium, Micrococcus, Aereobacter, Flavobacterium and Erwin There are considerable populations of phosphate solubilizing bacteria in soil and in plant rhizospheres $[7,15]$.

\subsection{Liquid Bio-fertilizer}

Liquid Bio-fertilizer a substance which helps to grow plants rapidly and produce fruits, flower and vegetable more quantity in proper time, otherwise fertilizer be a compound which fulfill the needed minerals or Clements require for the growth of plants and vegetables to grow and fruits in proper time. [4]

Liquid Bio-fertilizer is natural fertilizers which are microbial inoculants of bacteria algae fungi alone or in combination and they augment the availability of nutrients to the plants. The liquid Bio fertilizers are suspension having agriculturally useful microbes, which fix atmospheric nitrogen and solubilize insoluble phosphates and make it available for the plants. $[3,5,8,14]$

\subsection{Factors Affect Plant Growth}

There are four primary factors that affect plant growth: light, water, temperature and nutrients. These four elements affect the plant's growth hormones, making the plant grow more quickly or more slowly. Changing any of the four can cause the plant stress which stunts or changes growth, or improves growth. It's important to learn as much as you can about each of the four factors and your own.

\subsection{Statement of Problem}

Cognition of the effect of detrimental caused by using immoderate or imbalanced and ensuing use of chemical fertilizers and other synthetic agricultural inputs that which leads to depletion or degradation of soil fertility status, environmental pollution, human health hazards at the same time destruction of natural ecosystem. The Department of Agriculture felt the need to promote Integrated Plant Nutrient Systems (IPNS) for sustainable agriculture where biofertilizer is one of the major components adding to mineral fertilizers and manures. Bio fertilizer Laboratory was therefore set up with a view to produce different types of bio fertilizers required in the field of agriculture for increasing crop production level, to improve soil fertility status, to minimize human health hazards problem, to minimize the use of chemical fertilizers at least by $45 \%$ of the country, to provide support to have meaningful organic farming/organic agriculture and to minimize environmental pollution at the same time to conserve natural eco-system in an eco-friendly way. $[10,13,15]$

\subsection{Objective}

Of this study were to produce $\mathrm{N}_{2}$ fix and phosphorus solubilizing liquid bio fertilizer and tostudy the effect of biofertilizer on plant growth.

\section{Methodology}

\subsection{Materials (Equipment's) Used}

Apparatus used for this research were include 15 liter of bucket, 1000-liter plastic pot, rumen, cow manure, plastic pipe, balance bottle and wire. 


\subsection{Reagents (Chemicals) Used}

The reagents used in this research are; morass, nonchlorinated water, whey/milk, fermi pan, silica phosphate (basalt) can be used.

\subsection{Preparation of Liquid Bio Fertilizer}

Two basic steps can be carried out for preparation of liquid bio fertilizer first prepare Nutrient of microbes and secondly Preparation of bio fertilizer first prepare microbial nutrient procedure prepare 15 liter of bucket then 2 liter of morass, 2 liter of milk/whey and 10liter of non-chlorinated water followed by gentile mixing secondly we do another experiment with the Procedu re prepare $1000 \mathrm{ml}$ of plastic pot within the pot we put the following ingredients; 100 liter of non-chlorinated water, 20 liter of fresh rumen, $40-50$ liter of fresh cow manure, $3 \mathrm{~kg}$ silica and phosphorus, $2 \mathrm{~kg}$ of rock dust (basalt) and $1 / 2 \mathrm{~kg}$ of fermi pan finally putting prepared microbe's nutrient from first step. mix together the plastic pot. Then finally make the following condition Creating airlock and Secure with wire up to air can escape but not return to barrel. For 15-days then the product ready to use as bio-fertilizer.

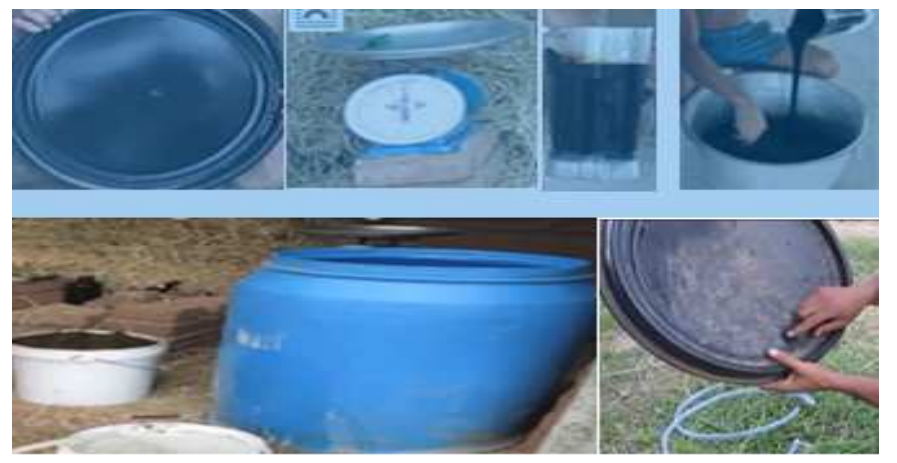

Figure 1. Schematics of the bio-fertilizer production material and preparation technics.

\subsubsection{Serial Dilution}

$54 \mathrm{ml}$ (i.e. $9 \mathrm{ml}$ for each test tube) of distilled water was added into 6 test tubes to dilute the sample. The prepared distilled water was foiled with aluminum and then sterilized at $121^{\circ} \mathrm{C}$ for $15 \mathrm{psi}$ and for $1 \mathrm{hrs}$ the sterilized distilled water was then cooled. Then serial dilution was done. Then $54 \mathrm{ml}$ of distilled water were shared for 6 test tube up to $9 \mathrm{ml}$ of distilled water then $1 \mathrm{ml}$ of samples filtrate of caffeine were taken and added into first distilled water test tube label $10^{-1}$ using pipette to dilute the sample. Then $1 \mathrm{ml}$ droplet of solution was taken from each of the $1^{\text {st }}$ test tube, and added to each $2^{\text {nd }}$ test tube label $10^{-2}$ This procedure was continued up to the $6^{\text {th }}$ test tube of sterilized distilled water for each sample (i.e., you make $10^{-1}-10^{-6}$ dilution for each sample) one after the other. $0.1 \mathrm{ml}$ of diluted sample was taken from each of 12 test tubes and inoculated into labeled agar plate (inoculation of the sample occur after agar solution were solidified on plate. This solidification processes may be take up to 20min) then by using sterilized spreader the sample was distributed. Finally, viable cell counted.

The bacteria can be counted by calculating C.F.U. i.e. Colony Forming Unit.

C.F.U. $=$ no, of colonies/inoculums size $(\mathrm{ml}) \mathrm{X}$ dilution factor C.F.U/ml

colony-forming unit (CFU) is a measure of viable bacterial or fungal cells.

For example, suppose the plate of the $10^{\wedge} 6$ dilution yielded a count of 130 colonies. Then, the number of bacteria in $1 \mathrm{ml}$ of the original sample can be calculated as follows:

Bacteria/ml $=(130) \times\left(10^{\wedge} 6\right)=1.3 \times 10^{\wedge} 8$ or $130,000,000$.
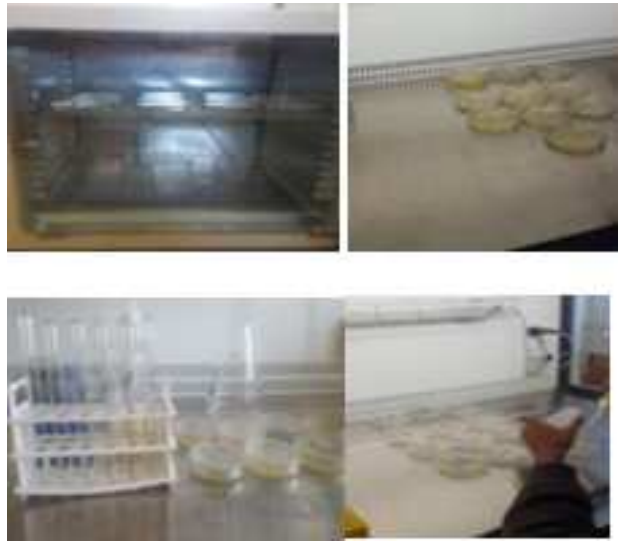

Figure 2. Serial dilution and incubation lab work.

Ingredients for preparation of broth

Table 1. Ingredients for Rhizobium Broth (YEM medium).

\begin{tabular}{lll}
\hline Sr no, & Ingredients & $\mathbf{G M} / \mathbf{m L}$ \\
\hline 1 & $\mathrm{~K}_{2} \mathrm{HPO}_{4}$ & 0.5 \\
2 & $\mathrm{MgSO}_{4}$ & 0.1 \\
3 & $\mathrm{Nacl}$ & 0.2 \\
4 & Yeast extract & 10 \\
5 & Manitol & 10 \\
\hline
\end{tabular}

Table 2. Ingredients for bacillus broth (PIKOVSKAYA medium).

\begin{tabular}{lll}
\hline Sr no, & Ingredients & GM/L \\
\hline 1 & Dextrose & 10 \\
2 & Calcium phosphate & 5 \\
3 & Ammonium sulphate & 0.5 \\
4 & Potassium chloride & 0.2 \\
5 & $\mathrm{MgSO}_{4}$ & 0.1 \\
6 & Manganese sulphate & 0.001 \\
7 & Ferrous sulphate & 0.01 \\
\hline
\end{tabular}




\subsubsection{Morphological Test}

Its deal shape and size of microbes by the tools compound microscope Morphologic test can be microbes characterize based on size and shape.

Gram staining characterization of microbial strain which have two categories first simple staining technic (single strain) and secondly compound (differential) staining technic.

\subsubsection{Gram Staining}

The Gram stain is almost always the first step in the preliminary identification of a bacterial organism. [7, 9] A smear was prepared by placing a drop of water on the slide and then transferring microorganism to the drop of water with a sterile cooled loop. It was mixed and spread by means a circular motion of the inoculating loop. Smear was air dried Crystal violet is the primary stain used first and stains all cells purple. Its function is to impart its color to all cells in order to establish a color contrast. Grams iodine, used as mordent in which this reagent is not only a killing agent, but also serves as a mordant a substance that increases the cells affinity for a stain. It does this by binding to the primary stain, thus forming an insoluble complex. The resultant crystal violet iodine complex serves to intensify the color of the stain. At this point, all cells will appear purple black. Ethyl alcohol, $95 \%$ is used as decolorizing agent in which this reagent serves as a dual function as a protein dehydrating agent and as a lipid solvent. By using this Gram negative bacteria become colorless. Safranin is used to stain red those cells that have been previously decolorized. Thus safranin is a counter stain since only gram negative cells undergo decolourization, they may now absorb the counterstain. Gram positive cells retain the purple color of the primary stain and gram negative bacteria appear as pink color using compound microscope 40x lenses. [5, 11, 14]

\subsubsection{Biochemical Test}

Biochemical test Chosen colonies were more characterize for a variety of biochemical test as well as activity sugar fermentation test, indole production test, Methyl Red (MR) test, Urease Test and Nitrate Reduction Test.

\section{(i). Methyl Red (MR) Test}

Methyl Red (MR) test is a biochemical test performed on bacterial species to detect the ability of an organism to produce stable acids end products (Mixed-acid fermentation) from supplied glucose. Some bacteria have ability to perform mixed acid fermentation of glucose in MR-VP medium. The products of mixed-acid fermentation are a complex mixture of acids, particularly lactate, acetate, succinate and format as well as ethanol and equal amounts of $\mathrm{H}_{2}$ and $\mathrm{CO}_{2}$. This causes the medium to acquire an acidic $\mathrm{pH}$. Methyl Red is a $\mathrm{pH}$ indicator, which remains red in color at a $\mathrm{pH}$ of 4.4 or less. $[7,8]$

Laboratory Procedure Methyl Red (MR) Test [8]

1) By using sterile inoculating loop, inoculate the microorganism that we identified into the fresh, sterile medium (glucose).

2) Leave the other broth inoculated (this will be a control).

3) Incubate the inoculated tube at $35-37^{\circ} \mathrm{C}$ for two to five days.

4) After incubation, obtain the broths from the incubator and add 5 drops of Methyl Red reagent to the broth.

5) Observe the color.

\section{(ii). Indole Test}

Indole test is the biochemical test performed on bacterial species to detect the ability of an organism to degrade the amino acid tryptophan and produce indole. Indole can be detected with Kovac's reagent or Ehrlich's reagent. Indole reacts with the aldehyde in the reagent tgive a red color which concentrates as a ring at the top. $[6,15]$

Laboratory Procedure of Indole Test [8]

1) Bacterium to be tested is inoculated in typtone broth.

2) Incubate overnight at $37^{\circ} \mathrm{C}$.

3) Add few drops of Kovac's reagent/Ehrlich's reagent are more sensitive in detecting indole production in anaerobes and non-fermenters.

4) Do not shake the tube and observe the result.

\section{(iii). Urease Test}

Urease broth is a differential medium that tests the ability of an organism to produce an exoenzyme, called urease that hydrolyzes urea to ammonia and carbon dioxide. The broth contains two $\mathrm{pH}$ buffers, urea, a very small amount of nutrients for the bacteria, and the $\mathrm{pH}$ indicator phenol red. $[14,13,4]$

\section{(iv). Nitrate Reduction Test}

It is a procedure that differentiates the members of azatobacter based on the ability to produce nitrate reductase enzyme which in turn hydrolyze nitrate to nitrite and will be eventually degraded to different nitrogen products such as nitrous oxide, nitrogen oxide, and ammonia. [7, 3]

1) Incubate aerobically at 35 to $37^{\circ} \mathrm{C}$ for up to $4-7$ days.

2) Observe a color change from green to blue along the slant.

Finally, we conserved the identified microbes with aseptic technic (plate to broth) as figure show below.

\section{Evaluate the Effectivity of Crop Growth}

The basic factor that affecting the plant growth were; light, moisture (water), temperature and nutrient in this experiment we take constant suitable condition of light and moisture The response can be obvious for plant growth of plant height (in meter) and maturity period within crops (maize) growing on the vent. Three treatments were conducted with prepared bio fertilizer, chemical fertilizer (urea and Dap) and control.

Modular representation of the process 


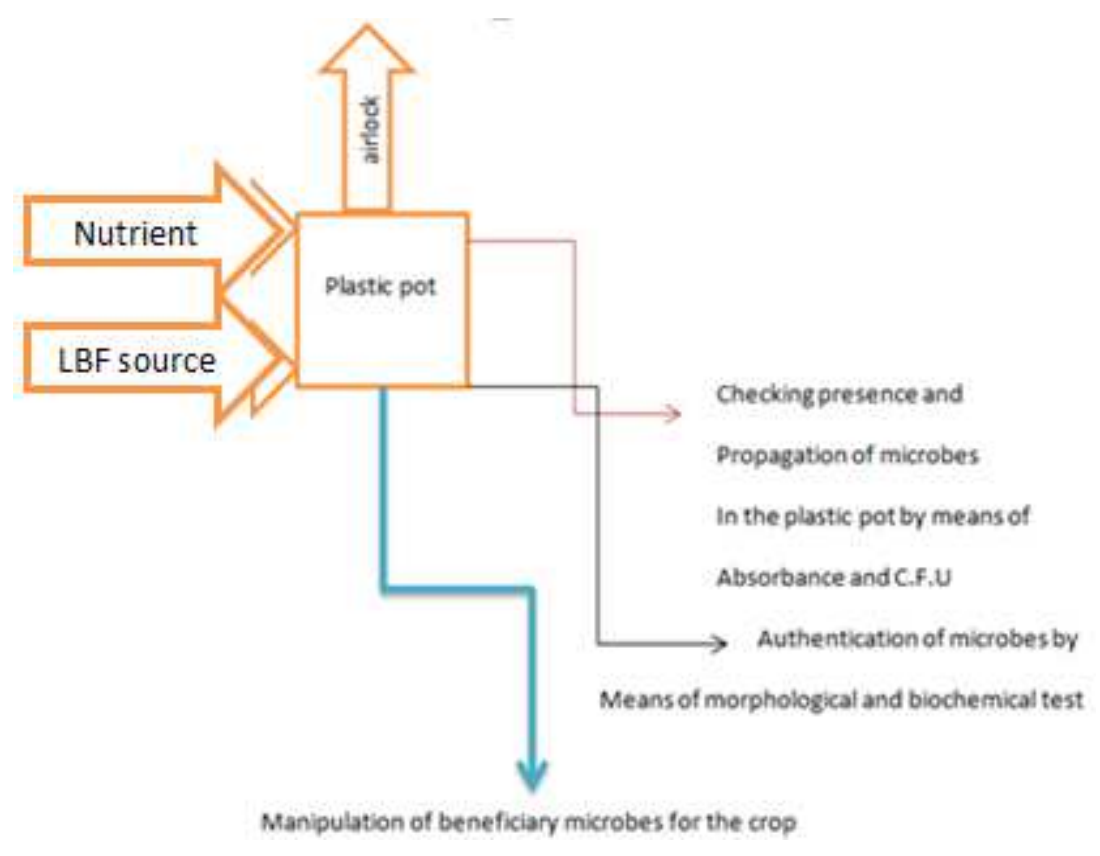

Figure 3. Modular representation of process.

Note. During the process characterization or authentication of bacterial broth we use medium separately (rhizobium and azatobactor) why microbes can grow different environment condition.

\section{Result and Discussion}

\subsection{Analysis of Microbial Growth Curve}

This analysis can be conducted because of checking some MOs can grow or not by using absorbance analysis technics by taking sample from plastic pot then checking microbial growth curve. Look the result obtained from the experiment the following table.

Table 3. Absorbance reading result.

\begin{tabular}{llllllllllll}
\hline Tim (hr) & $\mathbf{0}$ & $\mathbf{1}$ & $\mathbf{2}$ & $\mathbf{3}$ & $\mathbf{4}$ & $\mathbf{5}$ & $\mathbf{6}$ & $\mathbf{7}$ & $\mathbf{8}$ & $\mathbf{9}$ & $\mathbf{1 0}$ \\
\hline Absobat 600nm & 1 & 1 & 1 & 3.24 & 3.7 & 4.9 & 5.6 & 6.5 & 6.3 & 6.3 & 6.3 \\
\hline
\end{tabular}

Graph of the curve will be as showed below.

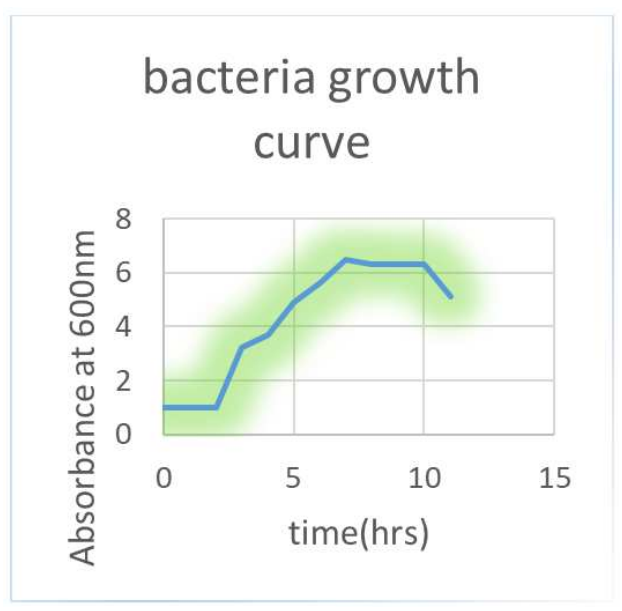

Figure 4. Bacterial growth curve.

Description of the above graph that indictors microbial growth curve that have four stage:
1) Lag phase - period adaptation from environment $(\mathrm{PH}$, conce. and temperature of media) (at time of 0-2).

2) Exponential growth phase accelerated growth phase rapid growth (at time of 3-7).

3) Stationary phase the phase balance going growth and death due to depletion of nutrient (one bacteria use as nutrient to the other) (at time of 8-10).

4) Death phase was the phase that declivity of the axis due to release out of life.

\subsection{Biochemical and Morphological Test}

\subsubsection{Morphological Test}

The following biochemical test conducted from taking sample from bio-fertilizer prepared from plastic pot after 15 days. Then the sample going to serial dilution to cont. biomass with the formula.

C.F.U. i.e. Colony Forming Unit.

C.F.U. $=$ no, of colonies/inoculums size $(\mathrm{ml}) \mathrm{X}$ dilution factor C.F.U/ml 
Like the following lab MOs cont. technics.

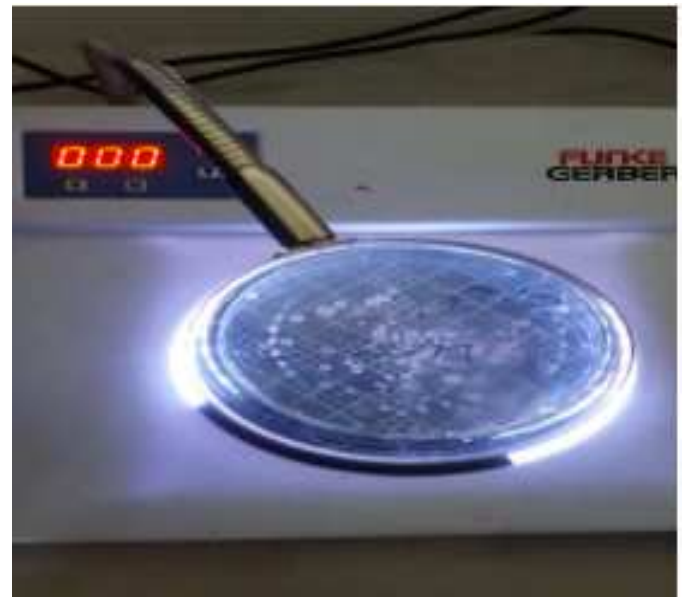

Figure 5. Counting colony forming unit.

\subsubsection{Biochemical Test}

Then from this Petri dish we take the sample (MOs) colony for preparing $50 \mathrm{ml}$ broth by certain two different media for Rhizobium YEM medium and for azotobact. pIKOVSKAYA medium because different microbes can grow in different media. then conducted the following biochemical test result.

Table 4. Biochemical and morphological test.

\begin{tabular}{lll}
\hline Test & rhizobium sp. & Azobacter sp. \\
\hline shape & strait rode & rode \\
Gram staining & $-\mathrm{ve}$ & $+\mathrm{ve}$ \\
Indole & $-\mathrm{ve}$ & $-\mathrm{ve}$ \\
Methyl red & $+\mathrm{ve}$ & $-\mathrm{ve}$ \\
Urease production & $+\mathrm{ve}$ & $-\mathrm{ve}$ \\
NR & $+\mathrm{ve}$ & $+\mathrm{ve}$ \\
& Carbohydrate fermentation & \\
Lactose & $-\mathrm{ve}$ & $-\mathrm{ve}$ \\
Maltose & $+\mathrm{ve}$ & $+\mathrm{ve}$ \\
Sucrose & $+\mathrm{ve}$ & $+\mathrm{ve}$ \\
\hline
\end{tabular}

Indole test like figure show bellow that Starch in the presence of iodine produces a dark-blue coloration of the medium, and a yellow zone around a colony in an otherwise blue medium indicates amylolysis activity.

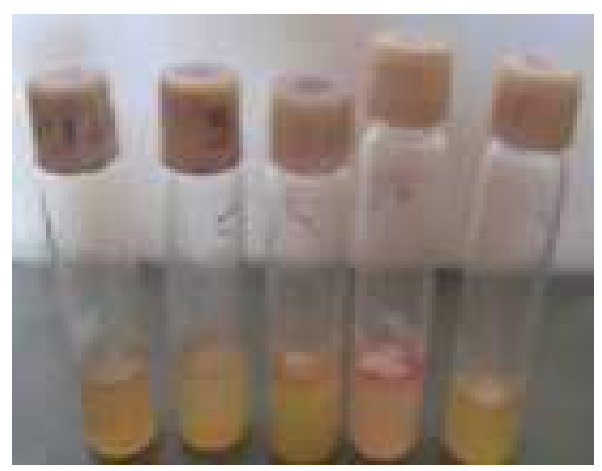

Figure 6. Indole test.

Fermentation of carbohydrate Positive result show -mainly gas production in their fermentation process in addition color change of media from red to yellow Negative result show No change of media color.

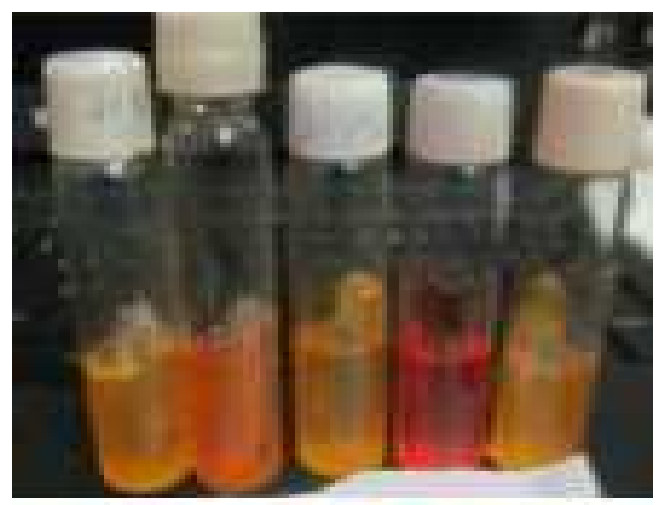

Figure 7. Carbohydrate fermentation test.

Effectivity of plant growth The basic factor that affecting the plant growth were; light, moisture (water), temperature and nutrient in this experiment we take constant suitable condition of light and moisture. The response can be obvious for plant growth of plant height (in meter) and maturity period. within crops (maize) growing on the vent.

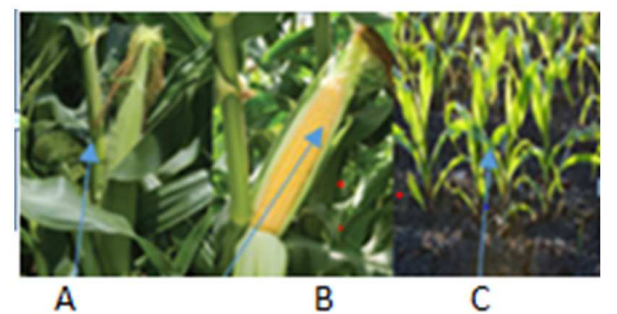

Figure 8. Effectivity of crops (maize) growth (control, LBF and CF.

When A stands for control (free from any manupulation); B stands for manupulated biofertilizer; $\mathrm{C}$ stands for chemical fertilizer.

\section{Conclusion}

The investigation of crops micro biomass has benefited from compressive ecological investigation on one-way and reductionist mechanistic discoveries on the other way. Both schools of thought are yielding increasingly profound insight into the ecological processes that govern plantmicrobe interactions as well as the molecular mechanisms that facilitate them. The generation of large isolate and characterization collections and the study of synthetic microbial communities in combination with plant genetic resources, will allow us to bridge this gap and to conduct reductionist, hypothesis driven studies in increasingly complex ecological contexts up to field tests. These advances have the potential to transform our understanding of plant-microbe interactions in nature and in agriculture, and will contribute significantly to the next green revolution.

The analysis evidence that lower concentration was found to show promoting effect on growth and productivity of plants. The fertilizing efficiency broth is due to the presence 
of micro and macro nutrients, at preferential levels. It can be conclude that the broth prepared using two types of organism which were isolated from Environmental sample or obtained from microbial bank in different institutes like Ethiobiodiversity can be used as environment friendly biofertilizers to substitutes fabricated hazardous chemical fertilizers. This will keep the fertile soil conditions for longer duration of time.

\section{Recommendation}

This study strongly recommended that farmer should be practiced the adaptation of such Economical, Environmental and time manageable way of bio-fertilizer rather daily use of chemical fertilizer in farm land for crops nutrient. and in other hand we protect and practiced natural resource management will be practiced such as protecting microbes from poison by means of adding mover chemical fertilizer and protecting water body specially rivers and air pollution from emersions of harm full gas to the atmosphere. For further researcher we recommended that should be analyze the microbes that doing micro-nutrient level for plant nutrients like K. Mobilizer bacteria.

\section{References}

[1] AGRA (2013) Africa Agriculture Status Report 2013 - Focus on staple crops. Nairobi: Alliance for a Green Revolution for Africa.

[2] Alston, J. M., G. W. Norton, and P. G. Pardey. (1995) Science under Scarcity. Ithaca, NY: Cornell University Press.

[3] Andrade, M., I. Barker, D. Cole, H. Dapaah, H. Elliott, S. Fuentes, W. Grüneberg, R. Aping, J. Kroschel, R. Labarta, B. Lemaga, C. Loechl, J. Low, J. Lynam, R. Mwanga, O. Ortiz, A. Oswald, and G. Thiele (2009) 'Unleashing the potential of sweet potato in Sub-Saharan Africa: Current challenges and way forward', CIP Working Paper. Lima: International Potato Center.

[4] ASTI-KARI (2009) Agricultural science and technology indicators survey. Unpublished surveys. Washington, D.C. and Nairobi: Agricultural Science and Technology Indicators and Kenya Agricultural Research Institute.

[5] Chen M, Alexander M. 1973. Survival of soil bacteria during prolonged desiccation. Soil Biol. Biochem. 5: 213-221.
[6] Moffett M. L, Giles JE, Wood BA. 1983. Survival of Pseudomonas solanacearum biovars 2 and 3 in soil: effect of moisture and soil type. Soil Biol. Biochem 15: 587-591.

[7] Morris, M. and D. Hoisington (2000) 'Bringing the Benefits of Biotechnology to the Poor. The role of the CGIAR Centers', in Qaim, M., A. F. Krattiger, and J. von Braun (eds) Agricultural Biotechnology in Developing Countries: Towards Optimizing the Benefits for the Poor, Boston: Kluwer Academic Publishers.

[8] Mose, L. O., H. O. Nyangito and L. G. Mugumieri (1997) 'An Analysis of the Socio-economic Factors which Influence Chemical Fertilizer Use among Smallholder Producers in Western Kenya', in Ransom, J. K. et al. (eds). Maize Productivity Gains through Research and Technology Dissemination: Proceedings of the Fifth Eastern and Southern Africa Regional Maize Conference. Arusha, Tanzania, June 1996.

[9] Mugendi, D. N (2011) 'Comparative Analysis of the Current and Potential Role of Legumes in Integrated Soil Fertility Management in East Africa' Fighting Poverty in Sub-Saharan Africa The Multiple Roles of Legumes in Integrated Soil Fertility Management, accessed 5 October 2013.

[10] Gupta A. K. 2004. The complete technology book on biofertilizers and organic farming. National Institute of Industrial Research Press. India.

[11] Wafula, J. and C. Falconi (1998) 'Agricultural Biotechnology Research Indicators', Kenya Discussion Paper No. 98-9 September 1998, The Hague: International Service for National Agricultural Research. Accesed 5 October 2010 $<$ www.ids.ac.uk>.

[12] Wambugu, F. M. (2001) Modifying Africa. How Biotechnology Can Benefit The Poor and Hungry. Accessed 5 August $2013<\mathrm{http}: / /$ www.ielrc.org $>$.

[13] Wambugu, F. M. and R. Kiome (2001) 'The Benefits of Biotechnology for Small-Scale Banana Producers in Kenya', ISAAA Policy Brief No. 22-2001. Accessed 5 August 2013 $<$ http://www.ielrc.org $>$.

[14] Wambugu, F. M. (2003) 'Development and Transfer of Genetically Modified Virus-resistant Sweet Potato for Subsistence Farmers in Kenya', Nutrition Reviews 61 (6). $\begin{array}{llll}\text { Accessed } & 5 & \text { August } & 2013\end{array}$ $<$ http://www.alibris.com/books/author/Wambugu,-Florence$\mathrm{M}>$.

[15] Wani, S. P. and Lee K. K., 2002. Population dynamics of nitrogen fixing bacteria associated with pearl millet (P. americanum L.), In biotechnology of nitrogen fixation in the tropics, University of Pertanian, Malaysia, 2130. 